\title{
COMMUNITY ENGAGEMENT ON MEDIA LITERACY (CE:ML) ECOSYSTEM: TOWARDS QUINTUPLE HELIX COLLABORATION AND RURAL SUSTAINABILITY
}

\author{
Norsiah Abdul Hamid ${ }^{1}$ \\ School of Multimedia Technology \& Communication, College of Arts and Sciences, Universiti Utara Malaysia. \\ (Email: nor1911@uum.edu.my) \\ Zauridah Abdul Hamid ${ }^{2}$ \\ School of Multimedia Technology \& Communication, College of Arts and Sciences, Universiti Utara Malaysia. \\ (Email: zauree@uum.edu.my) \\ Sabrina Mohd Rashid ${ }^{3}$ \\ School of Multimedia Technology \& Communication, College of Arts and Sciences, Universiti Utara Malaysia. \\ (Email: sabrina@uum.edu.my) \\ Mohd Sobhi Ishak ${ }^{4}$ \\ School of Multimedia Technology \& Communication, College of Arts and Sciences, Universiti Utara Malaysia. \\ (Email: msobhi@uum.edu.my) \\ Abbas Ghanbari Baghestan 5 \\ Department of Communication, Faculty of Social Sciences, University of Tehran. \\ (Email: ghanbari.abbas@ut.ac.ir)

\section{Hadi Khaniki ${ }^{6}$} \\ Department of Communication, Faculty of Social Sciences, University of Tehran. \\ (Email: hadi.khaniki@gmail.com) \\ Seyed Mehdi Etemadifard ${ }^{7}$ \\ Department of Communication, Faculty of Social Sciences, University of Tehran. \\ (Email: etemady@ut.ac.ir)
}

Received date: 12-10-2019

Revised date: 12-12-2019

Accepted date: 16-12-2019

Published date: 29-12-2019

To cite this document: Hamid, N. A., Hamid, Z. A., Rashid, S. M., Ishak, M. S., Baghestan, A. G., Khaniki, H., \& Etemadifard, S. M. (2019). Community Engagement on Media Literacy (CE:ML) Ecosystem: Towards Quintuple Helix Collaboration and Rural Sustainability. International Journal of Law, Government and Communication, 4(17), 94-101.

DOI: $10.35631 /$ ijlgc.417009

\begin{abstract}
Internet proved that community members are increasingly exposed to various gadgets and media applications, which undoubtedly can have positive and negative impacts on their lives. Yet, despite interest in and the emergence of examples of inspirational community engagement and the increasing usage of media among citizens, relatively little is known about the scale as well as the ecosystems of the emerging media literacy of Malaysian rural citizens. The objective of this research is to identify the important elements in conducting community engagement on media literacy programs in the rural community. A program which is called "Community Engagement on Media Literacy" (CE: $M L)$ has been designed to assist the community members in utilizing the
\end{abstract}


media in their daily lives. This program is a collaboration between faculty members and students of a university and committee members of a mosque in the northern district of Malaysia. The community selected is one large community area in the northern state containing about 3,000 members. This area is unique since it covers rural and sub-urban areas containing seven villages and five structured residential areas of low-to-middle-income families. Researchers were directly involved with the media literacy program, hence get a better chance to observe the processes of CE: ML. The program took two months to be completed, from February until April 2019. Altogether, 18 activities have been conducted, which mostly involved school children and youth ranging from 6 to 18 years old. Based on observation method, 15 elements of CE: ML ecosystem have been identified, namely Coordination, Communication, Contents Creation, Stakeholders Support, Location, Supporting Facilities, Targeted audience and their willingness to participate, Funding and Costing, Risk, Scheduling, Spirit of Volunteerism, Development of Soft skills, Multi-racial and International Unity, Training of trainers and Visibility and promotion of programs. At the time of the implementation, CE: ML was designed on double helix collaboration, merging two actors - university and the local community. Hence, based on the actual experience, CE: ML program can be improved to be extended to "quintuple helix" collaboration involving the university, government, private sector, local community, and the environment.

Keywords: Media Literacy, Community Engagement, Higher Education, Quintuple Helix, Rural Sustainability

\section{Introduction}

Current practice in many university campuses worldwide including Malaysia, is to emphasize on real-world learning experiences for students through diversified opportunities such as service-learning, problem-based learning, gap year opportunity, and community-based research. Among the focus is community engagement projects in which universities identified certain communities for knowledge transfer purposes. Community engagement means participation with a community of people, rather than an individual citizen (Cavaye, 2004), which means that engagement arrangements need to incorporate the diversity and dynamics of communities, issues of community representation and power, and the potentially conflicting goals of sub-communities.

The Carnegie Foundation defines community engagement as "collaboration between institutions of higher education and their larger communities for the mutually beneficial exchange of knowledge and resources in a context of partnership and reciprocity" (New England Resource Center for Higher Education, 2018). OECD (2001) has urged for the government-citizen relations in policy-making which led to the term community engagement. Three elements became the main focus of OECD idea, namely information, consultation and active participation. Information and Communication Technology (ICT) is also a powerful tool for the successful of the CE program (OECD, 2001).

Community engagement in the context of higher education (HE) refers to the "collaboration between HE institutions and their larger communities (local, regional/state, national, global) for the mutually beneficial exchange of knowledge and resources in a context of partnership and reciprocity" (Driscoll, 2009, p. 6). Shuib and Azizan (2015) argue that community engagement will span the full range of higher education institution endeavors by bringing significant social and environmental benefits as well as contributing to improvements in educational outcomes 
and to economic growth of their communities. HEIs are thus not only viewed as the providers of a qualified workforce and research capacity; they are also seen as powerful drivers of innovation which can bring positive changes in the development of a country.

Current development in the usage of media and Internet proved that community members are increasingly exposed to various gadgets and media applications, which undoubtedly can have positive and negative impacts on their lives. Malaysia was ranked top five globally and highest in Southeast Asia for mobile social media penetration, as reported by Hootsuite and We Are Social in their latest Digital 2019 report (News Straits Times, 31 January 2019). Unsurprisingly, Facebook stays as the favorite application to date (Global Stats, 2019).

Yet, despite interest in and the emergence of examples of inspirational community engagement and the increasing usage of media among citizens, relatively little is known about the scale as well as the ecosystems of the emerging media literacy of Malaysian rural citizens. Good practices across Malaysia show that media literacy are effective and efficient policy tools at policymakers' hands to reduce territorial disparities, bridge the public-private sphere and to boost economic growth, employability of vulnerable social groups, including B40s by improving the performance of rural development policies and programs. In addition, the awareness on parental control by parents among Internet users are worrying, in which only $62.4 \%$ parents aware and take action to ensure child online safety (Malaysian Communication and Multimedia Commission, 2019). Therefore, a media literacy program is needed to strengthen community members' expertise in the use of media as well as raise their awareness of media risk. Hence, the objective of this article is to discuss the elements required for community engagement on media literacy ecosystem specifically for rural community in Malaysia.

\section{Literature Review}

As proposed by McNall, Reed, Brown, and Allen (2009), in order to cultivate the communityuniversity collaboration, partnership management and opportunities for the co-creation of knowledge are crucial. Laing (2016) pointed out that university-community engagement should have two broad purposes: (i) it should aim to mobilize and combine university knowledge and community experience to address social disadvantage and exclusion, to promote the idea of a fair society, and (ii) it should complement and collaborate with the university's service to business activities by focusing on all those areas of our daily lives that are of profound material and civic importance but which are typically seen as "non-economically productive activity", such as caring, sustainable development, self-management of health and well-being, voluntary activity and the development of citizenship. Thus, focusing on various issues at the community level is crucial in order to ensure the impact towards the community members.

A huge number of impacts were gained by the community engagement projects between university and community. For instance, community members which get involved with campus event have more favorable impression towards the university than those who had not attended any university event (Bruning, McGrew \& Cooper, 2006). Universities that develop serious and fully strategic programmes of community-university engagement can add greater color and richness to their existing teaching and research programmes, as well as providing tangible benefits to their local communities (Laing, 2016). A community engagement project in Indonesia which addressed severe acute malnutrition in children younger than five years of age was also successful due to the acknowledgement of a continual effort of community mobilization (Bait, Rah, Roshita, Amaheka, Chrisnadarmania \& Lino, 2019). In addition, 
Rhinesmith and Stanton (2018) found that the educational, social, and community benefits of community engagement programs could be useful for public libraries to consider in developing or augmenting media literacy initiatives.

Having a holistic and impactful ecosystem is crucial in the context of community engagement on media literacy. Yet, four main gaps in implementing a well-functioning ecosystem, namely (i) geographic and cultural gap, (ii) age and experience gap, (iii) expectations and communications gap, and (iv) funding and risk gap (Social SEED Interreg Europe, 2017). These gaps are also critical in achieving a good practice and holistic support when conducting a community project.

\section{Methodology}

A program which is called "Community Engagement on Media Literacy" (CE:ML) has been designed by the researchers to assist the community members in utilizing the media in their daily lives. This program is a collaboration between faculty members and students of a university, and committee members of a mosque in the northern district of Malaysia. The community selected is one large community area in the northern state containing approximately 3,000 household members. This area is unique since it covers rural and sub-urban areas containing seven villages and five structured residential areas of low-to-middle-income families. Researchers were directly involved with the media literacy program, hence get a better chance to observe the processes of CE: ML. The program took two months to be completed, from February until April 2019. Altogether, 18 activities related to media literacy enhancement have been conducted, which mostly involved school children and youth ranging from 6 to 18 years old.

\section{Findings and Discussion}

Based on the observation done before, during and after the CE program, the researchers have come up with 15 elements of Community Engagement on Media Literacy (CE:ML) ecosystem, as follows:

\section{Coordination}

Coordination among all parties is crucial in community engagement program. Cavaye (2004) and OECD (2001) also emphasized the important of coordination in CE program. In the context of media literacy, coordination was required through formal and informal meetings among the organizer and the stakeholders. The formal meeting was conducted in the university with the attendance from the faculty's top management, the faculty members, the researchers, and the mosque's Imam and committee members. Informal meetings were also done at the community's venue to get to know the community better, for instance their background, socioeconomic status, needs analysis pertaining to media literacy and some suggested content for the CE: ML.

\section{Communication}

Having various parties involved in a community engagement program is not easy. We have to utilize some communication channels, especially WhatsApp group, email, and Facebook. There are times when a committee member of the mosque does not have a smartphone, therefore we communicate via SMS and call. 


\section{Contents Creation}

Teaching media literacy to community is no easy task. The content we created ranging from the basic software skills such as word processing, spreadsheet, presentation, poster design, online quiz, through to the social media marketing, creativity, and online ethics. These modules have been designed to increase awareness on media and assist the community members in using and utilizing media for daily lives and income generation. The contents were also designed based on the needs analysis done prior to the start of the program.

\section{Stakeholders Support}

Conducting any $\mathrm{CE}$ requires full support from relevant stakeholders. The stakeholders involved in the CE:ML are the mosque committee members, parents, community members and university. This project managed to achieve the objectives with the support from all the stakeholders. In this regard, Bait, Rah, Roshita, Amaheka, Chrisnadarmania and Lino (2019) emphasized that securing strong leadership of key stakeholders, such as heads of districts, women's empowerment organizations, community and religious leaders is essential for strengthening community engagement, as these stakeholders are listened to and respected.

\section{Selection of Location}

In conducting a CE, location is one important consideration for the organizer and stakeholders. The organizer decided to conduct the CE:ML at the nearby community which is only $18.5 \mathrm{~km}$ from the university main campus. Hence, it is deemed convenient for the faculty members and students to travel here and forth.

\section{Supporting Facilities}

Conducting a CE:ML requires a lot of equipment. Among the crucial hardware are computers, LCD projector, network, proper cabling system, together with appropriate software. Since all the activities have been conducted at the participants' place, i.e. mosque's hall, residential area hall, and community hall, the faculty members and students brought their own computers and other supporting equipment. The mosque has been equipped with Wi-Fi, so there is no issue on the network connectivity, whereas at other residential area and community halls, students have to use their own mobile telephone's hotspot for the purpose of connecting to the Internet.

\section{Targeted Audience and Their Willingness to Participate}

A Community Planning Toolkit developed by Community Places (2014) highlighted the 'hard to reach groups' such as young people, older people, minority groups or socially excluded groups. Similarly, in CE:ML, our targeted groups among others are B40 families and rural community. They consist of school children, youth, school dropouts, housewives, senior citizens, the disable people and working adults. However, we faced difficulties in getting participations except for school children, even though we have put consideration on conducting programs during weekends and evening sessions for them to be able to participate. But we do understand that people have various daily commitments and in order to reach them, we have to change our approach, by considering doing the program at their place for their ease instead of them having to come to the respective venue which may incur more cost and time.

\section{Funding and Costing}

Financial support is critical in any CE program. That is why we aim for quintuple helix collaboration whereby we shall get funds and other supports from the government agencies and private sectors. Financial support was also emphasized by Cavaye (2004) and OECD (2001). 


\section{Risk}

Conducting a community engagement program is no easy task. Having various groups of actors, risks are among the crucial factors to be taken into consideration. We need to take into account the risk faced by faculty members, students, participants and committee members. The risk can be reduced among faculty members and students if the program conducted on campus, but it increases the risk on the community members whereby they have to travel to the university, and vice versa.

\section{Scheduling}

Scheduling is also a major consideration when planning a community engagement program. $\mathrm{CE}$ needs proper planning. We do face problems whereby some of the programs need to be rescheduled due to unforeseen events, such as classes/examinations conducted over the weekend, school holidays, public holidays etc. On the community side, since many of the committee members are working, so they can only give more attention after their business hours or during weekend. To get a mutual agreement on the date was not an easy task.

\section{Spirit of Volunteerism}

Community engagement program offers a volunteerism opportunity especially among students and participants. Students were not paid for their community works, but they have put much effort in ensuring the success of the project. They sacrificed their time, energy, some pocket money and their weekend to get involve with the CE: ML.

\section{Development of Soft Skills}

This program has sharpened the soft skills of students and participants such as communication skill, leadership and teamwork, time management, life-long learning, ethics and professionalism, critical thinking and problem solving, plus creativity and innovative.

\section{Multi-racial and International Unity}

The CE:ML involved multi-racial and multi-religious actors. Faculty members, students, and community members who get together for the program are Malay, Indian, Chinese, Siam, and also ethnics of Sabah and Sarawak. This has ensured some moments of unity among Malaysians. There were also a few international students involved in the CE:ML who came from China and Indonesia.

\section{Training of Trainers}

Before the programs were conducted with the community members, trainers were first being trained by the faculty members. The training sessions were done systematically during classes and out-of-classes period. They were also required to prepare proposals and present the ideas to the academic staff so that the focus of programs will be on media literacy.

\section{Visibility and Promotion of Programs}

Visibility of the programs has been done by promoting it via various media by the faculty members and students. Among the efforts were distributing printed flyers at public spots, sharing posters via WhatsApp, face-to-face promotion at nearby schools, and announcement by the Imam (Head of Mosque) before the Friday prayers. 


\section{Way Forward}

\section{From Double Helix to Quintuple Helix Collaboration}

At the time of the implementation, CE:ML was designed on double helix collaboration, merging two actors - university and local community. Hence, based on the actual experience, CE:ML program can be improved to be extended to "quintuple helix" collaboration involving university, government, private sector, local community and the environment.

\section{Sustainability Issue in Community Engagement Program}

Key to sustainability is all of the above-mentioned findings, from coordination, communication, through to the visibility and promotion of the program. If the organizer and stakeholders make a proper plan and ensure great implementation, a CE program will be sustained. In the case of CE:ML, the stakeholders also demand that the focus and content be made variety, to include motivation, time management and English language series of workshops. If all stakeholders play their role, sustainability of CE program can surely be achieved. We always believe that in order to help reduce poverty and increase the income of B40s, they must be empowered with knowledge and skills, not by giving cash as cash is not the king anymore. Knowledge and skills are intangible, yet sustained and doubled.

\section{Conclusion}

This article highlighted a research conducted on community engagement focusing on media literacy in rural area. The objective of the research is to identify the important elements in conducting community engagement on media literacy program particularly for the rural community. A program which is called "Community Engagement on Media Literacy" (CE:ML) has been designed to assist the community members in utilizing the media in their daily lives. This program is a collaboration between faculty members and students of a university and committee members of a mosque in the northern district of Malaysia. 15 elements of CE:ML ecosystem have been identified and discussed. At the time of the implementation, CE:ML was designed on double helix collaboration, merging two actors - university and local community. Hence, based on the actual experience, CE:ML program can be improved to be extended to "quintuple helix" collaboration involving university, government, private sector, local community and the environment.

\section{Acknowledgements}

This article is a part of a research grant sponsored by Universiti Utara Malaysia, Malaysia and University of Tehran, Iran (UUM S/O Code: 14349).

\section{References}

Bait, B.R., Rah, J.H., Roshita, A., Amaheka, R., Chrisnadarmania, V. \& Lino, M.R. (2019). Community engagement to manage acute malnutrition: implementation research in Kupang district, Indonesia. Bull World Health Organisation, 97:597-604. doi: http://dx.doi.org/10.2471/BLT.18.223339

Bruning, S.D., McGrew, S. \& Cooper, M. (2006). Town-gown relationships: Exploring university-community engagement from the perspective of community members. Public Relations Review, 32(2), 125-130.

Cavaye, J.M. (2004). Governance and community engagement - The Australian experience in participatory governance: Planning, conflict mediation and public decision making in civil society. In W.R. Lovan, M. Murray \& R. Shaffer (Eds). pp. 85-102 Ashgate Publishing 
https://www.researchgate.net/profile/Jim_Cavaye/publication/268254917_Governance _and_Community_Engagement_-The_Australian_Experience/links/5657 fa5808ae4988a7b585d7/Governance-and-Community-Engagement-The-AustralianExperience.pdf

Community Places. (2014). Community planning toolkit - community engagement. Accessed from https://www.communityplanningtoolkit.org/sites/default/files/ Engagement.pdf

Driscoll, A. 2009. Carnegie's new community engagement classification: Affirming HE's role in community. New Directions for HE 147: 5-12.

Global Stats. (2019). Social media stats Malaysia. Accessed from http://gs.statcounter.com/social-media-stats/all/malaysia

Laing, S. (2016). Community engagement is what universities should be for. Retrieved on 15 November 2019, from https://www.timeshighereducation.com/blog/communityengagement-what-universities-should-be.

Malaysian Communication and Multimedia Commission (MCMC). (2019). Internet users survey 2018. Accessed from https://www.skmm.gov.my/skmmgovmy/media/ General/pdf/Internet-Users-Survey-2018-(Infographic).pdf

McNall, M., Reed, C.S., Brown, R. \& Allen, A. (2009). Brokering community-university engagement. Innovative Higher Education. 33(5), 317-331. https://doi.org/10.1007/s10755-008-9086-8

New England Resource Center for Higher Education. (2018). Carnegie community engagement $\begin{array}{lllll}\text { classification. Retrieved on } 15 \quad \text { November } & 2019 \text { from }\end{array}$ http://nerche.org/index.php?option=com_content\&view=article\&id=341\&Itemid=618.

News Straits Times, 31 January 2019. Malaysia ranks top 5 globally in mobile social media penetration, highest in region. Accessed from https://www.nst.com.my/lifestyle/bots/2019/01/456119/malaysia-ranks-top-5globally-mobile-social-media-penetration-highest.

OECD. (2001). Engaging Citizens in Policy-making: Information, consultation and public participation. Accessed from http://gpsaknowledge.org/wpcontent/uploads/2014/10/PB-GOV-Engaging-Citizens-in-Policy-Making.pdf

Rhinesmith, C. \& Stanton, C.L.U. (2018). Developing media literacy in public libraries: Learning from community media centers. Public Library Quarterly, 37(4), 420-440. https://doi.org/10.1080/01616846.2018.1525527

Shuib M. \& Azizan, S.N. (2015). Emerging practices in university-community engagement in Malaysia. In: Collins C.S., Neubauer D.E. (eds) Redefining Asia Pacific Higher Education in Contexts of Globalization: Private Markets and the Public Good. International and Development Education. Palgrave Pivot, New York.

Social SEEDS Interreg Europe. (2017). Methodology and good practices on quintuple helix cooperations: Making better use of social entrepreneurship collaborations in policy improvements. Accessed from https://www.interregeurope.eu/fileadmin/ user_upload/tx_tevprojects/library/file_1536063863.pdf 